\title{
A novel splice site mutation in a Becker muscular dystrophy patient
}

\author{
Claire Bartolo, Audrey C Papp, Pamela J Snyder, Mary S Sedra, \\ Arthur H M Burghes, Colin D Hall, Jerry R Mendell, Thomas W Prior
}

\begin{abstract}
A Becker muscular dystrophy patient was found to have a single base substitution at the $5^{\prime}$ end of intron 54. This single base substitution disrupts the invariant GT dinucleotide within the $5^{\prime}$ donor splice site and was shown to cause an out of frame deletion of exon 54 during mRNA processing. This is predicted to produce a truncated dystrophin protein which is more consistent with a DMD phenotype. However, small quantities of normal mRNA are also transcribed and these are sufficient to produce a reduced amount of normal molecular weight dystrophin and give rise to a milder BMD phenotype. This indicates that a single base substitution at an invariant dinucleotide of the splice site consensus sequence may still allow read through of the message and allow the production of some normal protein. This shows that there are a greater number of possible intronic mutations that can lead to a mild phenotype and it also underlines the importance of performing cDNA analysis when screening for small gene alterations in the BMD patient population. ( $\mathcal{H}$ Med Genet 1996;33:324-327)
\end{abstract}

Key words: Becker muscular dystrophy; splice site mutation.

Columbus, Ohio

43210, USA

A C Papp

P J Snyder

M S Sedra

$T$ W Prior

Department of Neurology, The Ohio State University, Columbus, Ohio 43210, USA

A H M Burghes

J R Mendell

Department of Neurology, The University of North

Carolina, Chapel Hill, North Carolina 27599, USA

C D Hall

Correspondence to: Dr Prior.

Received 11 July 1995 Revised version accepted for publication

7 December 1995 detect owing to the very large size of the gene. The majority of the small mutations identified in these muscular dystrophy patients have resulted in premature termination of protein trans- lation, giving rise to unstable dystrophins and the more severe DMD phenotype. ${ }^{6} \mathrm{Un}$ fortunately, since these types of mutation do not produce dystrophin, they provide little or no information about the structural and functional domains of the protein. On the other hand, mutations identified in the less severely affected BMD patients often maintain the translational reading frame and allow for the synthesis of a correctly localised dystrophin protein. For this reason, it becomes important to identify small gene alterations in BMD patients. The BMD small mutations provide insight into the mechanisms involved in generating the milder phenotype.

Although there have been numerous reports of DMD point mutations, at present there are few published BMD point mutations. ${ }^{6}$ Roberts $e t a l^{7}$ reported a $\mathrm{G}$ to $\mathrm{C}$ transversion at the $3^{\prime}$ end of intron 56 of the dystrophin gene. This single base substitution caused partial inactivation of the splice acceptor site of exon 57, resulting in activation of a cryptic splice acceptor site located $18 \mathrm{bp}$ downstream from the normal one, which maintained the translational reading frame. A similar mutation that affected normal splicing was reported by Hagiwara et al. ${ }^{8}$ This involved a $G$ to $T$ substitution at position -1 of the $5^{\prime}$ splice site of intron 13 and resulted in the production of a dystrophin protein with an in frame deletion of exon 13. Finally, Wilton et $a l^{9}$ described a $\mathrm{C}$ to $\mathrm{A}$ base change at position +3 of intron 19 which resulted in the deletion of exon 19 from the dystrophin mRNA. Since this mutation affected a base in the consensus sequence that is only $60 \%$ conserved, ${ }^{10}$ some normal mRNA was also observed. Thus, the reported BMD mutations are consistent with the reading frame rule, which proposes that deletions or duplications causing BMD allow for the production of dystrophin because the translational reading frame is maintained. ${ }^{11}$ We now report a splice site mutation, which by sequence analysis was predicted to produce a severely truncated protein and was therefore more consistent with a DMD mutation. However, the mutation allowed for the synthesis of a reduced amount of normal molecular weight dystrophin and gave rise to a milder BMD phenotype. 


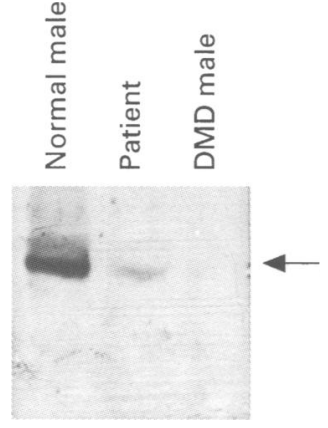

Figure 1 Western blot analysis of dystrophin from normal male muscle samples, the BMD patient, and a DMD negative control. The arrow indicates normal dystrophin at $427 \mathrm{kDa}$. The western blot was stained with the antibody Dys-2.

\section{Materials and methods}

RNA ANALYSIS

Total RNA was isolated from $30 \mathrm{mg}$ of a muscle biopsy sample obtained from an unaffected person and from the affected patient with TRI$\mathrm{zol}^{\mathrm{TM}}$ reagent (BRL). A total of $1.5 \mu \mathrm{g}$ of total RNA was reverse transcribed into cDNA using $0.5 \mu \mathrm{g} / \mu \mathrm{l}$ oligo $\mathrm{dT}_{(12-18)}(\mathrm{BRL})$ and $200 \mathrm{U} \mathrm{Su}-$ perscript II reverse transcriptase (BRL) in a $20 \mu \mathrm{l}$ reaction containing $20 \mathrm{mmol} / 1$ Tris- $\mathrm{HCl}$ (pH 8.4), $50 \mathrm{mmol} / 1 \mathrm{KCl}, 2.5 \mathrm{mmol} / 1 \mathrm{MgCl}_{2}$, $0.5 \mathrm{mmol} / 1 \mathrm{dNTPs}$, and $10 \mathrm{mmol} / \mathrm{l} \mathrm{DTT}$. The template and oligo dT primer were initially incubated at $70^{\circ} \mathrm{C}$ for 10 minutes to enhance priming and the reverse transcription reaction was then performed at $42^{\circ} \mathrm{C}$ for 50 minutes.

Seminested PCR was carried out using the prepared cDNA as template. The first round reaction was performed in a $100 \mu \mathrm{l}$ volume containing $20 \mathrm{mmol} / 1$ Tris- $\mathrm{HCl}$ (pH 8.4), $50 \mathrm{mmol} / 1 \mathrm{KCl}, 2 \mathrm{mmol} / \mathrm{l} \mathrm{MgCl}_{2}, 10 \mathrm{ng}$ of each primer (53F: 5'-GAAAGAATTCAGAATCAGTGGGATG-3'，59R: 5'-TCGAGGTGATCTTGGAGA-3' and 2.5 U Taq DNA polymerase (BRL) for 30 cycles of $94^{\circ} \mathrm{C}$ for one minute, $50^{\circ} \mathrm{C}$ for two minutes, and $72^{\circ} \mathrm{C}$ for three minutes with an initial denaturation step at $94^{\circ} \mathrm{C}$ for five minutes. An aliquot was removed from the first round PCR product and used as a template in the second round reaction. This was carried out as described above except that $0.2 \mathrm{mmol} / \mathrm{l} \mathrm{dNTPs}$ and $5 \mathrm{U}$ Taq DNA polymerase (BRL) were added to the reaction mix. The nested primer set included the forward primer, $53 \mathrm{~F}$, and a reverse primer, $57 \mathrm{R}$ (5'-GTACATCGTTCTGCT-3'). The PCR products were then separated on a $2.5 \%$ agarose gel and visualised with ethidium bromide. The purified products were sequenced using the ds DNA Cycle Sequencing System (BRL). Primers were end labelled with gamma $\left[{ }^{32} \mathrm{P}\right]-$ ATP. Product from the sequencing reaction was analysed using a $5 \%$ denaturing polyacrylamide gel.

\section{ANALYSIS OF GENOMIC DNA}

PCR amplification and sequence analysis were accomplished following the same procedure as described previously. ${ }^{12}$ The oligonucleotide primers used for PCR amplification and sequence analysis were: 54F: 5'-GTTTGTCCTGAAAGGTGGGTTAC-3' and 54R: 5'TTATCGTCTTGAACCCTCCCAAG-3'.

\section{PROTEIN ANALYSIS}

The immunocytochemical and western blot procedure for dystrophin were the same as that described in detail previously. ${ }^{1314}$

\section{Results and discussion}

A muscle biopsy specimen was obtained from a BMD patient for dystrophin protein analysis. Western blot analysis using both an N-terminal antibody and the C-terminal antibody specific to the last 17 amino acids of the dystrophin Cterminus (Dys-2, Nova-Castra Labs, Newcastle upon Tyne, UK), indicated the presence of an apparently normal sized but reduced dystrophin, approximately $10 \%$ of normal (fig 1). Since there was no evidence of a small gene deletion or duplication, by multiplex PCR and Southern blotting, we analysed DNA for the presence of point mutations and CDNA for the presence of splice type mutations. The DNA was isolated from the patient's muscle biopsy and was screened by a heteroduplex analysis approach, ${ }^{15}$ while muscle cDNA was analysed for splice type mutations as indicated by the presence of aberrant bands using primer sets spanning the dystrophin message.

All cDNA PCRs from the patient's muscle resulted in normal sized products, except for the product spanning nucleotides $7871-8735$ (numbering as in ref 16). The RT-PCR product from the patient sample yielded two bands: one band of the expected size ( $864 \mathrm{bp}$ ) but present at approximately $10 \%$ of the normal control, as well as a more intensely staining product of reduced size ( $700 \mathrm{bp})$. The abnormal band was gel purified and sequenced and was found to lack nucleotides 8081-8236, which corresponds to exon 54 (fig 2). The deletion of exon 54 results in a translational frameshift with the new reading frame terminating in exon 55. Therefore, in addition to a stable aberrantly spliced mRNA that has a frameshifting deletion of exon 54, the BMD patient transcribes small quantities of normal mRNA that are sufficient to produce the approximately $10 \%$ levels of dystrophin observed on the western blot.

Sequence analysis of genomic DNA amplified using primers flanking exon 54 showed a $T$ to $C$ transition at position +2 of the $5^{\prime}$ splice site of intron 54. This single base substitution disrupts the GT dinucleotide within the $5^{\prime}$ donor splice site, ${ }^{1718}$ causing the deletion of exon 54 during mRNA processing. For normal splicing to occur, the splicing system requires introns to begin with GT and end with AG. With few exceptions, ${ }^{19}$ these dinucleotides are invariant and required for correct splicing. Since this was an isolated case of BMD and given the high frequency of germline mosaicism in Duchenne muscular dystrophy, the possibility of somatic mosaicism for the point mutation exists. However, sequence analysis from the muscle biopsy showed only the abnormal sequence. It is therefore unclear how the splicing apparatus was able to recognise the mutant splice donor site and still produce some normal message. In comparison, the BMD mutation described by Wilton et al ${ }^{9}$ involved a base outside the highly conserved GT dinucleotide and therefore resulted in some normal transcript.

A scoring system was devised by Shapiro and Senapathy ${ }^{20}$ to determine optimal splice site sequences based on the frequency of each nucleotide in normal splice sequences. The wild type sequence at the $5^{\prime}$ donor site of intron 54 (AG:GTATGA) scores $81 \%$ using this method, indicating a high degree of similarity to the actual consensus sequence (AG:GTA/CAGT) established by Mount. ${ }^{18}$ The mutated sequence at this site (AG:GCATGA) scores $\sim 64 \%$ and since normally used splice site sequences have a score $>70$, the point mutation at the invariant 
A
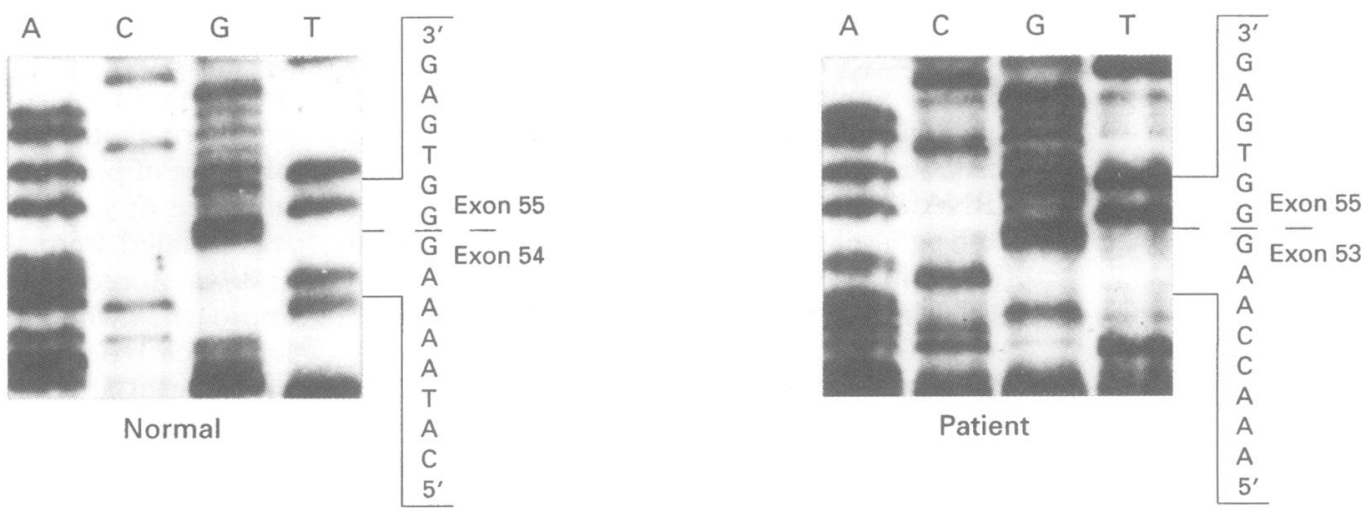

B
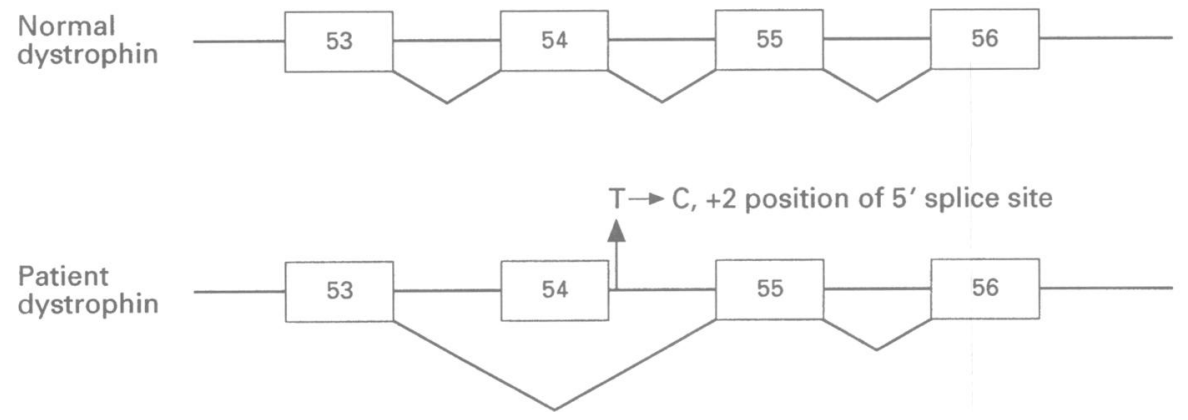

Figure 2 Dystrophin cDNA sequence analysis. (A) Portions of the sequencing gel with a normal control on the left and the BMD patient on the right are shown. A comparison of the nucleotide sequences of the two PCR products showed that the patient sample is deleted for exon 54, and that exon 53 is precisely joined to exon 55. (B) The two PCR products represent normally spliced (above) and misspliced (below) dystrophin mRNA. Exon 54 has been skipped owing to the $T$ to $C$ transition at the donor splice site of intron 54. Exons are represented by open boxes while solid lines represent introns.

GT dinucleotide is predicted to prevent normal mRNA splicing.

This patient had a mild phenotype and was shown to produce a low level of dystrophin. The patient is at present 9 years old and can walk well on both his heels and toes. There is only mild slowing when he runs and he can rise from a squat position with only minimal hand support on his knee. Thus, the low abundance of normal transcript was sufficient to synthesise enough dystrophin to give rise to the milder phenotype. It has been observed in other genetic diseases that variations outside the highly conserved $5^{\prime}$ GT or 3' AG dinucleotides often result in the production of both abnormal and normal spliced mRNA transcripts. We have shown that a point mutation at the invariant dinucleotide of the consensus sequence may still allow read through of the mutation and production of some normal transcript. This increases the number of possible intronic mutations that can occur in the dystrophin gene, which allow for the synthesis of sufficient levels of dystrophin to produce the milder phenotype. This may also account for the fact that very few BMD mutations have been identified using genomic DNA analysis. Intron mutations that affect splice sites, branch sites, or create cryptic splice sites may be responsible for producing the reduced amount of dystrophin and the milder phenotype in many of the BMD patients. Strategies based on cDNA analysis will therefore be most successful in finding more BMD small mutations.

The authors acknowledge the photographic assistance of Arthur Weeks and Clara Murray. This work was supported by a grant from the Muscular Dystrophy Association.

1 Hoffman EP, Fischbeck KH, Brown RH, et al. Characterization of dystrophin in muscle-biopsy specimen from patients with Duchenne's or Becker's muscular dystrophy. N Engl f Med 1988;318:1363-8.

2 Darras BT, Blattner P, Harper JF, Spiro AJ, Alter S, Francke U. Intragenic deletions in 21 Duchenne muscular dystrophy (DMD)/Becker muscular dystrophy (BMD) familes studied with the dystrophin cDNA: location of breakpoints on HindIII and BglII exon-containing fragment maps, meiotic and mitotic origin of mutations. Am f Hum Genet 1988,43:620-9.

3 Liechti-Gallati S, Koenig M, Kunkel LM, et al. Molecular deletion patterns in Duchenne and Becker type muscula dystrophy. Hum Genet 1989;81:343-8.

4 Gillard EF, Chamberlain JS, Murphy EG, et al. Molecula and phenotypic analysis of patients with deletions within the deletion-rich region of the Duchenne muscular dystrophy (DMD) gene. Am ₹ Hum Genet 1989;45:507-20.

5 Hu X, Ray PN, Murphy EG, Thompson MW, Worto RG. Duplicational mutation at the Duchenne muscula dystrophy locus: its frequency, distribution, origin and phenotype/genotype correlation. Am f Hum Genet 1990 46:682-95.

6 Roberts RG, Gardner RJ, Bobrow M. Searching for the 1 in 2,400,000: a review of dystrophin gene point mutations. Hum Mutat 1994;4:1-11.

7 Roberts RG, Passos-Bueno MR, Bobrow M, Vainzof $M$ Zatz $M$. Point mutation in a Becker muscular dystrophy patient. Hum Mol Genet 1992;2:75-7.

8 Hagiwara Y, Nishio $\mathrm{H}$, Kitoh Y, et al. A novel point mutation $\left(\mathrm{G}^{-1}\right.$ to $\left.\mathrm{T}\right)$ in a $5^{\prime}$ splice donor site of intron 13 of the $\left(\mathrm{G}^{-1}\right.$ to $\mathrm{T}$ ) in a 5 splice donor site of intron 13 of the dystrophin gene results in exon skipping and is responsible 54:53-61.

9 Wilton SD, Johnsen RD, Pedretti JR, Laing NG. Two Wilton SD, Johnsen RD, Pedretti JR, Laing NG. Two
distinct mutations in a single dystrophin gene: identification of an altered splice-site as the primary Becker muscular dystrophy mutation. Am f Med Genet 1993;46: 563-9. 
10 Padgett RA, Grabowski PJ, Konarska MA, Seiler S, Sharp PA. Splicing of messenger RNA precursors. Annu Rev Biochem 1986;55:1119-50.

11 Monaco AP, Bertelson CJ, Liechti-Gallati S, Moser H, Kunkel LM. An explanation for the phenotypic differences between patients bearing partial deletions of the DMD locus. Genomics 1988;2:90-5.

12 Prior TW, Bartolo C, Pearl DK, et al. Spectrum of small mutations in the dystrophin coding region. $\mathrm{Am} f \mathrm{Hum}$ Genet 1995;57:22-33.

13 Burrow K, Coovert DD, Klein CJ, et al. Dystrophin expression and somatic reversion in prednisone-treated and untreated Duchenne dystrophy. Neumlogy 1991;41: 662-6.

14 Klein CJ, Coovert DD, Bulman DE, Ray PN, Mendell JR, Burghes AHM. Somatic reversion/suppression in Duchenne muscular dystrophy (DMD): evidence supporting chenne muscular dystrophy (DMD): evidence supporting fibers. Am f Hum Genet 1992;50:950-9.

15 White MB, Carvalho M, Derse D, O'Brien SJ, Dean M. Detecting single base substitutions as heteroduplex polymorphisms. Genomics 1992;12:301-6.

16 Koenig M, Monaco AP, Kunkel LM. The complete sequence of dystrophin predicts a rod-shaped cytoskeleta protein. Cell 1988;53:219-28.

17 Breathnach R, Chambon P. Organization and expression of ukaryotic split genes coding for proteins. Annu Rev Biochem 1981;50:349-83.

18 Mount SM. A catalogue of splice junction sequences. Nucleic Acids Res 1982;10:459-72.

19 Jackson IJ. A reappraisal of non-consensus mRNA splicesites. Nucleic Acids Res 1991;19:3795-8.

20 Shapiro MB, Senapathy P. RNA splice junctions of different classes of eukaryotes: sequence statistics and functional implications in gene expression. Nucleic Acids Res 1987; implications 